\title{
Initial report on feasibility of PET/CT-based image-guided moderate hypofractionated thoracic irradiation in node-positive non- small cell lung Cancer patients with poor prognostic factors and strongly diminished lung function: a retrospective analysis
}

Chukwuka Eze ${ }^{1 *}$ D, Julian Taugner ${ }^{1}$, Olarn Roengvoraphoj ${ }^{1}$, Nina-Sophie Schmidt-Hegemann ${ }^{1}$, Lukas Käsmann ${ }^{1,2,3}$, Cherylina Wijaya ${ }^{4}$, Claus Belka ${ }^{1,2,3}$ and Farkhad Manapov ${ }^{1,2,3}$

\begin{abstract}
Background: To determine the feasibility of PET/CT-based image-guided moderate hypofractionated thoracic irradiation (Hypo-IGRT) in locally advanced node-positive non-small cell lung cancer patients with highly compromised pulmonary function.
\end{abstract}

Method: Eight highly-selected and closely monitored patients with highly diminished pulmonary function (FEV1 $\leq 1.0$ $\mathrm{L}$ and/or DLCO-SB $\leq 40 \%$ and/or on long-term oxygen therapy) were treated with Hypo-IGRT. Planning was based on 18F-FDG-PET/CT and 4D-CT in the treatment position. Hypo-IGRT was delivered to a total dose of 45 Gy (ICRU) in 15 daily fractions under strict image-guidance. Vital capacity (VC), forced expiratory volume in $1 \mathrm{~s}$ (FEV1), and single-breath diffusing capacity of the lung for CO (DLCO-SB) were analyzed prior to, 3 and 6 months after Hypo-IGRT.

Result: Eight patients with stage IIIA-C NSCLC (8th TNM Ed.) completed Hypo-IGRT. The median follow-up was 29.4 months. The median age was 64 years. Four, three and one patient(s) presented with COPD GOLD IV, III and II, respectively and 5 patients (63\%) were on long-term oxygen therapy. The median PTV was 226.9 cc (range: 100.17-379.80 cc). Median PFS and OS were 19 and 34.3 months. The 6 months and 1-year OS rates were 100, $87.5 \%$, respectively. The 6- and 12- months PFS rates were 87.5 and $52.5 \%$. Three patients developed local failure. Median initial VC, FEV1 and DLCO-SB was $1.69 \mathrm{~L} / 64.8 \%$ predicted (range: $1.36-2.66 \mathrm{~L} / 33-80 \%$ ), $1 \mathrm{~L} / 39.4 \%$ predicted (range:0.78-1.26 L/28-60\% predicted) and 33.3\% (range: 13.3-54\%) predicted, respectively. Median values for VC, FEV1, DLCO-SB 3 and 6 months after Hypo-IGRT were $2.05 \mathrm{~L} / 56.35 \%$ predicted (range: $1.34-2.33 \mathrm{~L} / 47-81.5 \%$ ), 1.08 L/47.5\% predicted (range: $0.74-1.60 \mathrm{~L} / 30.8-59.59 \%$ ), $38.55 \%$ (range: $24-68 \%$ ) and $1.64 \mathrm{~L} / 66 \%$ predicted (range: $1.41-2.79 / 35.5-75.5 \%), 1.0 \mathrm{~L} / 47 \%$ predicted (range: $0.65-1.28 \mathrm{~L} / 24.5-54.10 \%), 31 \%$ (range: $27-43 \%$ ), respectively. Mean lung dose was 9.4 Gy (range: 5.3-11.6 Gy) and V20 for both lungs was 15\% (range: 6-19\%). Mean esophageal dose was 12.76 Gy (range: 2.1-26.7 Gy). There was no case of grade 2 or higher radiation pneumonitis. Four patients developed grade 2 radiation esophagitis.

(Continued on next page)

\footnotetext{
* Correspondence: Chukwuka.Eze@med.uni-muenchen.de

'Department of Radiation Oncology, University Hospital, LMU Munich,

Marchioninistrasse 15, 81377 Munich, Germany

Full list of author information is available at the end of the article
}

(c) The Author(s). 2019 Open Access This article is distributed under the terms of the Creative Commons Attribution 4.0 International License (http://creativecommons.org/licenses/by/4.0/), which permits unrestricted use, distribution, and reproduction in any medium, provided you give appropriate credit to the original author(s) and the source, provide a link to the Creative Commons license, and indicate if changes were made. The Creative Commons Public Domain Dedication waiver (http://creativecommons.org/publicdomain/zero/1.0/) applies to the data made available in this article, unless otherwise stated. 
(Continued from previous page)

Conclusion: Hypo-IGRT can be considered for individual and closely monitored patients with locally advanced node-positive NSCLC with highly compromised pulmonary function. No severe pulmonary toxicity and significant decline of pulmonary function parameters was observed in our cohort. Currently, this protocol is being assessed in an ongoing single-centre prospective study.

Keywords: Hypofractionated radiotherapy, Image-guided radiotherapy, NSCLC, Thoracic radiotherapy

\section{Introduction}

The contemporary standard of care for stage IIIA-C NSCLC consists of surgery for medically operable subclassifications based on the Robinson criteria for stage IIIA disease or concurrent chemoradiotherapy (CRT) followed by consolidation therapy with Durvalumab with markedly improved survival rates based on the results of the PACIFIC trial [1].

CRT is often associated with increased acute and chronic toxicity, specifically pneumonitis and esophagitis [2]. In patients with poor performance status, CRT is not feasible as possible treatment-related side effects outweigh potential benefit. Additionally, patients with node-positive disease will often present with general comorbidities and impaired pulmonary function. High-risk patients with an FEV $1 \leq 1 \mathrm{~L}$ or DLCO-SB $\leq 40 \%$ predicted or on long-term oxygen therapy are unsuitable candidates for concurrent or sequential CRT and thus receive at best palliative treatment or best supportive care (BSC).

Stereotactic ablative radiotherapy (SABR) is an established treatment modality for early-stage NSCLC due to highly conformal delivery of high-dose radiotherapy to tumors whilst sparing adjacent organs at risk (OARs) and a proven very high local control rate of over $90 \%[3,4]$.
Several studies have reported on the feasibility of hypofractionated radiotherapy in locally advanced (LA-) NSCLC demonstrating respectable results. However, these studies generally failed to include patients with poor performance status and highly compromised pulmonary function (see Table 1) [6, 7, 9-12]. We previously published a case report of 2 such patients successfully treated at our institution [13]. In this retrospective study, we present a follow-up analysis of eight such high-risk patients.

\section{Material and methods \\ Patient cohort}

Following institutional review board approval, we retrospectively reviewed the medical charts of 8 patients with histologically proven stage IIIA-C NSCLC (UICC 8th edition), poor performance status (ECOG-PS $\geq 2$ ) treated between $04 / 14$ and 06/17 and were not eligible for surgical resection, conventional radiotherapy or concurrent CRT based on their highly compromised pulmonary function defined as FEV1 $\leq 1.0 \mathrm{~L}$ and/or DLCO-SB $\leq 40 \%$ and/or on long-term oxygen therapy and registered comorbidities and thus underwent hypofractionated image-guided radiotherapy (Hypo-IGRT) to a total of 15 fractions in 3 Gy single fractions $\left(\mathrm{BED}_{10}=58.5 \mathrm{~Gy} ; \alpha / \beta=10 \mathrm{~Gy}\right)$ at our institution. All patients were discussed at the

Table 1 Studies examining hypofractionation protocols

\begin{tabular}{|c|c|c|c|c|c|c|}
\hline Study & PTV median & D total lung & D oesophagus & D heart & Pneumonitis & Esophagitis \\
\hline Amini et al. 2012 [5] & - & - & - & - & $\geq$ G2: $14(11.8 \%)$ & $\geq$ G2: $12(10.1 \%)$ \\
\hline Agolli et al. 2015 [6] & $\begin{array}{l}180 \mathrm{cc} \\
(73-682 \mathrm{cc})\end{array}$ & $\begin{array}{l}(a / \beta=3 G y) \\
V 20<25-30 \% \\
\text { Mean dose } \leq 15 G y\end{array}$ & $\begin{array}{l}(a / \beta=3 G y) \\
V 42<32 \%\end{array}$ & $\begin{array}{l}(a / \beta=3 G y) \\
V 33<25 \%\end{array}$ & $\begin{array}{l}\text { Acute: G3-4 (6\%) } \\
\text { Late: G3-2 (3\%) } \\
{ }^{\circ} 4 / 5: 0\end{array}$ & $\begin{array}{l}\text { Acute: G3-3 } \\
\text { (5\%) } \\
\text { Late: G3-1 (2\%) } \\
\text { G4/5: } 0\end{array}$ \\
\hline $\begin{array}{l}\text { Westover et al. } 2015 \\
\text { [7] }\end{array}$ & $\begin{array}{l}50 G y: \\
673 \pm 75 c c \\
55 G y: \\
646 \pm 96 c c \\
60 G y: \\
454 \pm 68 c c\end{array}$ & $\begin{array}{l}\text { For all dose steps: } \\
\text { V18<37\% } \\
\text { Mean dose < } \\
18 \mathrm{~Gy} \\
1500 \text { cc } 15.5 \mathrm{~Gy} \\
1000 \text { cc } 16.3 \mathrm{~Gy}\end{array}$ & $\begin{array}{l}<5 \text { cc 51.3Gy } \\
\text { Max. dose: } 55.3 G y\end{array}$ & $\begin{array}{l}<15 \text { cc } 39.5 G y \\
\text { Max. dose: } 48.9 G y\end{array}$ & $\begin{array}{l}\text { 50Gy: } 5 \\
\text { (33.3\%) } \\
\text { 55Gy: } 4(19.0 \%) \\
\text { 60Gy: } 4(21.1 \%)\end{array}$ & $\begin{array}{l}\text { 50Gy: } 0 \\
\text { 55Gy: } 1(4.8 \%) \\
\text { 60Gy: } 1(5.3 \%)\end{array}$ \\
\hline Swanick et al. 2015 [8] & $\begin{array}{l}421.2 c c \\
(46.6-2666.6 \\
c c)\end{array}$ & $\begin{array}{l}\text { V20 < 30\% } \\
\text { Mean dose <20Gy }\end{array}$ & $\begin{array}{l}\text { Mean dose < } \\
\text { 34Gy } \\
\text { Max dose: 63.8Gy }\end{array}$ & $\begin{array}{l}\text { Mean Dose < } \\
\text { 20Gy }\end{array}$ & $\begin{array}{l}\text { G3-1 (1.4\%) } \\
\text { G4/5: } 0\end{array}$ & $\begin{array}{l}\text { G3-3 }(4.2 \%) \\
\text { G4-0 } \\
\text { G5-1 (1.4\%) }\end{array}$ \\
\hline Pollom et al. 2016 [9] & $\begin{array}{l}139 \text { cc } \\
(20-746 \text { cc) }\end{array}$ & $\begin{array}{l}V 18<37 \% \\
\text { MLD < } 18 \text { Gy } \\
1500 \text { cc } 15.5 \mathrm{~Gy} \\
1000 \text { cc } 16.3 \mathrm{~Gy}\end{array}$ & $\begin{array}{l}<5 \text { cc } 51.3 G y \\
\text { Max. dose: } 55.3 G y\end{array}$ & $\begin{array}{l}<15 \text { cc } 39.5 G y \\
\text { Max. dose: } 48.9 G y\end{array}$ & $\begin{array}{l}4(9.5 \%) \\
\text { [1 G4 Bronchiopleural } \\
\text { fistula] }\end{array}$ & $5(11.9 \%)$ \\
\hline
\end{tabular}


multidisciplinary tumor board following adequate staging via positron emission tomography with 2-deoxy-2-[fluorine-18] fluoro-d-glucose integrated with computed tomography (18F-FDG-PET/CT), endobronchial ultrasound with sampling and contrast-enhanced MRI of the brain as is common practice at our center. All patients received a radiotherapy dose adhering to a mean lung dose of less than 20 Gy, calculated from lung dose distributions corrected to equieffective doses at 2 Gy per fraction (EQD2) using the linear-quadratic model and an $\alpha / \beta$ of $2.5 \mathrm{~Gy}$ and the NTCP model in accordance with Kong et al. [14, 15] and normal tissue dose-volume constraints of other organs based on RTOG 0937 [16] in compliance with NCCN recommendations [17].

The patients were monitored closely during the course of radiotherapy and routinely underwent computed tomography $(\mathrm{CT})$ of the chest and upper abdomen or $18 \mathrm{~F}-$ FDG-PET/CT follow-up examination every 3 months after completion of radiotherapy and repeat imaging studies and clinical examinations ensuing every 3 months for the first 2 years, biannually in the following 2 years and annually from year 5 onwards. Lung function was assessed by pulmonary function tests (PFT) evaluating VC, FEV1 and DLCO-SB every 3 months for the first year following Hypo-IGRT and was assessed when available (see Fig. 1).

\section{Hypo-IGRT}

Hypo-IGRT was performed following induction chemotherapy in 3 patients and as definitive treatment in 5 . All patients underwent 18F-FDG-PET/CT and fourdimensional computed tomography (4D-CT) (10 sequential scans in all respiratory phases) in the treatment position immobilized in a vacuum-based and alpha cradle immobilization system.

The 4D-CT was matched with PET/CT for better definition of the target volume. The range of tumor motion was $1-4 \mathrm{~mm}$ in every dimension. Gross tumor volume (GTV) included the primary tumor and involved lymph node(s) (short axis $\geq 1 \mathrm{~cm}$ and/or PET-positive) postinduction chemotherapy in the respective patients. The internal target volume (ITV) was defined through the overlap of GTVs delineated on 10 phases of 4D-CT. Clinical target volume was not generated to limit pulmonary exposure. An isotropic margin of $5 \mathrm{~mm}$ was added to ITV to generate the planning target volume (PTV). The treatment was calculated on $3 \mathrm{~mm}$ grid with Collapse-Cone algorithm. Total dose delivered to the PTV was 45 Gy in 15 fractions, 5 times per week and was prescribed per ICRU with corrections for lung inhomogeneity. Pulmonary dose-volume parameters were calculated with total lung volume minus PTV. Mean lung dose (MLD), averages of ipsilateral and contralateral lung doses were obtained. Radiotherapy was delivered by linear accelerator (Elekta Synergy/Versa HD, Stockholm, Sweden) using $6 \mathrm{MeV}$ 8-9 coplanar fixed photon beams. Image guidance was performed with kilovoltage-conebeam CT prior to each treatment. Toxicity monitoring was performed twice weekly to record any side effects. Dose constraints for the OARs (i.e., esophagus, spinal cord, lung, heart/pericardium etc.) were adopted from universal survival models in addition to published tissue properties.

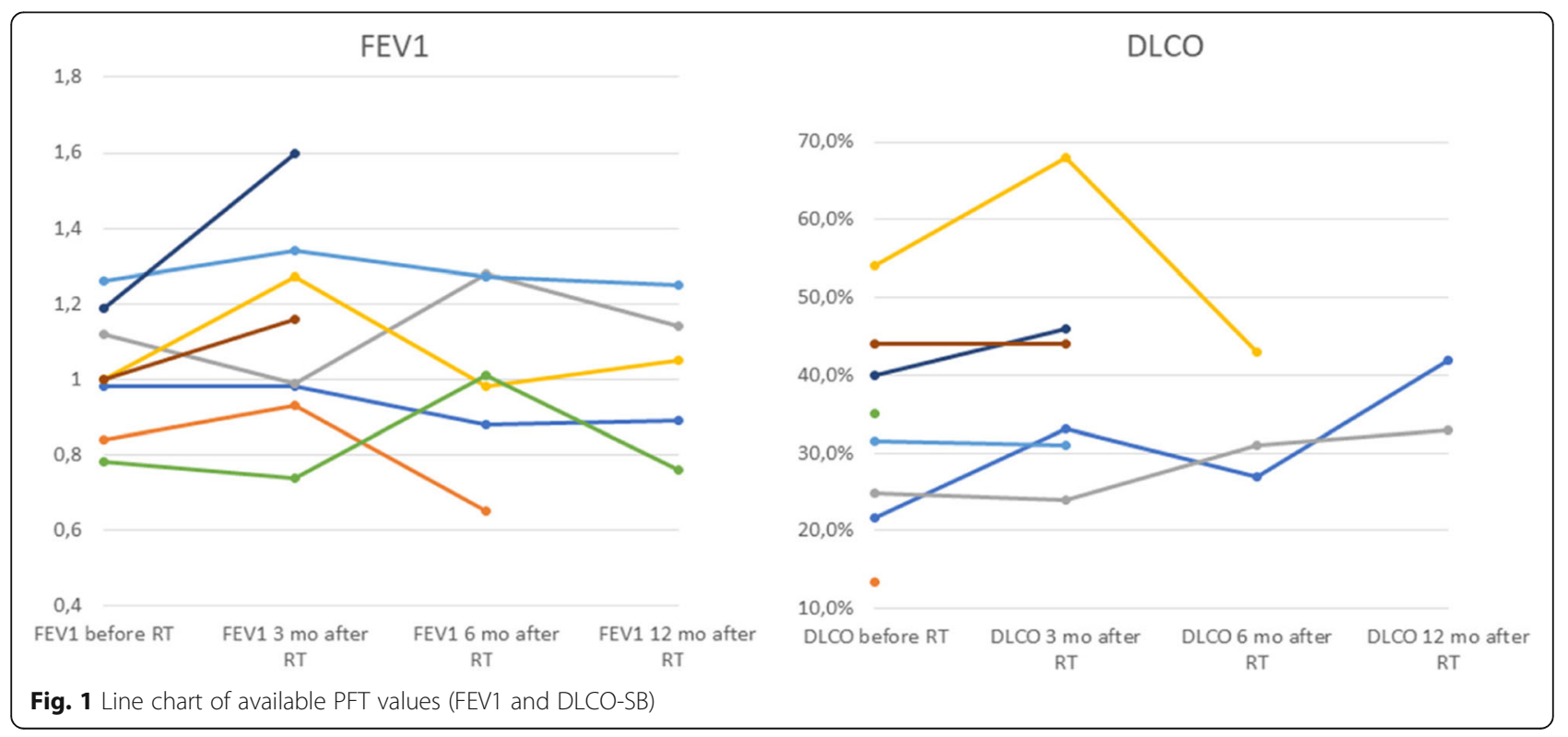




\section{Treatment tolerability}

Patients were closely monitored, and toxicity was graded according to the Common Terminology Criteria for Adverse Events (v4.03).

\section{Statistical analysis}

Statistical analysis was performed using IBM SPSS software version 24 (IBM, New York, USA). Overall and progression-free survival were calculated from the date of initial pathological diagnosis. Kaplan-Meier survival analysis and log-rank test were used to evaluate progressionfree and overall survival.

\section{Results}

Eight patients completed Hypo-IGRT. The median age was 64 years. Four, three and one patients presented with stage IIIA, IIIB and IIIC (8th TNM Edition), respectively. However, the patient who presented ab initio with stage IIIC disease died 7 months after initial diagnosis. Seven patients were assigned an Eastern Cooperative Oncology Group Performance Score (ECOG PS) 2 and 1 patient ECOG PS 3. Four, three and one patient(s) presented with COPD GOLD IV, III and II, respectively and 5 patients $(63 \%)$ were on long-term oxygen therapy. Three patients received chemotherapy prior to HypoIGRT. The median PTV was $226.9 \mathrm{cc}$ (range: 100.2379.8). Median initial VC, FEV1 and DLCO-SB was 1.69 L/64.8\% predicted (range: $1.36-2.66 \mathrm{~L} / 33-80 \%$ ), $1 \mathrm{~L} /$ $39.4 \%$ predicted (range:0.78-1.26 L/28-60\% predicted) and $33.3 \%$ (range: $13.3-54 \%$ ) predicted, respectively. Median values for vital capacity (VC), FEV1, DLCO-SB 3 and 6 months after Hypo-IGRT were $2.05 \mathrm{~L} / 56.35 \%$ predicted (range: $1.34-2.33 \mathrm{~L} / 47-81.5 \%$ ), $1.08 \mathrm{~L} / 47.5 \%$ predicted (range: $0.74-1.60 \mathrm{~L} / 30.8-59.59 \%$ ), 38.55\% (range: $24-68 \%$ ) and $1.64 \mathrm{~L} / 66 \%$ predicted (range: 1.41-2.79/35.5-75.5\%), $1.0 \mathrm{~L} / 47 \%$ predicted (range: $0.65-$ $1.28 \mathrm{~L} / 24.5-54.10 \%$ ), $31 \%$ (range: $27-43 \%$ ), respectively (see Fig. 1). PFT values for some patients were not available at various time points during follow-up. Mean lung dose was 9.4 Gy (range: 5.3-11.6 Gy). V15 and V20 for both lungs were $22 \%$ (range: $10-25 \%$ ) and 15\% (range: 6$19 \%$ ), respectively (see Table 2 ).

The median follow-up was 29.4 months. Three patients developed local failure. The median PFS and OS were 19 and 34.3 months (see Figs. 2 and 3), respectively. The 6 months and 1 - and OS rates were 100 and 87.5\%, respectively. The 6- and 12- months PFS rates were 87.5 and $52.5 \%$, respectively. Mean esophageal dose was 12.76 Gy (range: $2.1-26.7$ Gy). There was no case of $\geq$ grade 2 radiation pneumonitis. However, 4 patients developed grade 2 radiation esophagitis.

\section{Discussion}

Since mid- to end of the 1990s, several studies have demonstrated feasibility of moderate hypofractionated thoracic radiation for node-positive LA-NSCLC with a variety of prescription doses ranging from 45 in 15 fractions to 75 in 28 fractions and differing outcomes regarding survival and toxicity [18]. Two previous studies examined in the abovementioned systematic review also included node-positive stage III patients with poor initial performance status. Nguyen et al. reported equivalence of moderate hypofractionated thoracic irradiation (45 Gy in 15 fractions) to conventional treatment regimens (6066 Gy in 30-33 fractions) in LA-NSCLC patients with borderline prognostic factors despite the fact that the patients in the hypofractionation group had inferior prognostic factors [5]. In a follow-up analysis by the same group, these findings were consolidated and demonstrated equipoise regarding local or distant control as well as overall survival compared to the standard normofractionated radiatiotherapy arms [10]. Accelerated hypofractionated protocols were associated with improved patient compliance and were more cost-effective.

Based on our prodigious literature research, we determined the 45 Gy in 3 Gy single fractions protocol to be the most appropriate and applicable in node-positive stage IIIA-B NSCLC patients with poor PS and strongly diminished lung function (FEV1 $\leq 1 \mathrm{~L}$ or DLCO $\leq 40 \%$ predicted) as these patients are not candidates for conventional treatment modalities and are thus condemned to palliative chemotherapy, radiotherapy alone or BSC associated with dismal prognosis [19].

We screened our retrospective institutional database to identify a corresponding cohort. Eight highly selected and closely monitored patients with node-positive stage III AC disease with initial PS ECOG 2-3, extensive comorbidities and highly compromised pulmonary function were included in the retrospective analysis. All patients completed initial diagnostic work-up including contrastenhanced cranial MRI and received Hypo-IGRT at our centre with a documented follow-up. Hypo-IGRT was applied according our in-house protocol. Importantly,

Table 2 Treatment characteristics

\begin{tabular}{llll}
\hline PTV & D total lung & D oesophagus & D heart \\
\hline Mean: $232.2 \mathrm{~cm}^{3}$ & V20: 15\% (range: 6-19\%) & Mean: 12.76 Gy & Mean: 5 Gy \\
Median: $226.9 \mathrm{~cm}^{3}$ & Mean: $9.4 \mathrm{~Gy}$ & (range: 2.1-26.7 Gy) & (range: 0.4-10 Gy) \\
(range: $100.2-379.8 \mathrm{~cm}^{3}$ ) & (range: 5.3-11.6 Gy) & & \\
\hline
\end{tabular}




\section{Progression-free survival}

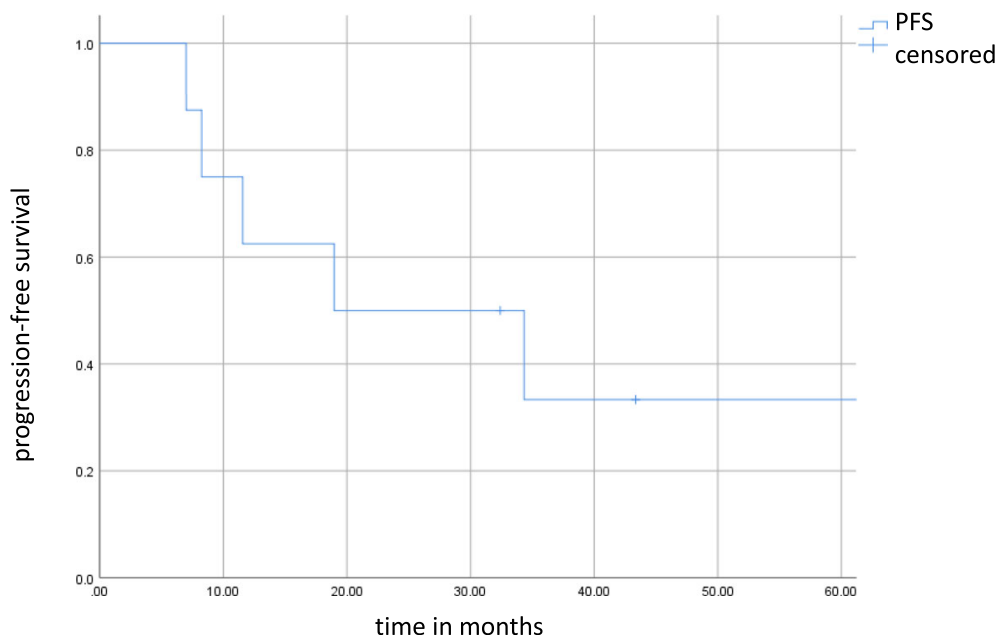

Fig. 2 Kaplan-Meier curve for progression-free survival. Tick marks indicate censoring

obligatory PET/CT and 4D-CT-based treatment planning including omission of the CTV and daily image-guidance during radiation delivery were obligatory [13].

Our results demonstrated with a durable median follow-up of 29.4 months that meticulously planned and monitored Hypo-IGRT can be considered in this highrisk subgroup. 6-, 12- and 18-month overall survival rates were encouraging. In addition, 12-month PFS was comparable to previous data from the University of Texas MD Anderson Cancer Centre group and fared favourably compared to conventionally treated patients $[5,10]$. Furthermore, particular emphasis must be made to the low rate of acute toxicity despite in the current study. Only one patient (12.5\%) had a 4-day treatment interruption because of exacerbation of pre-existing severe COPD Gold IV and was hospitalized. No case of $>\mathrm{G} 2$ radiation pneumonitis was documented.

As a result of various risk factors i.e. poor performance status and highly reduced pulmonary function, moderate hypofractionation with a total tumor dose of 45 in $3 \mathrm{~Gy}$ single fractions (corresponding $\mathrm{BED}_{10} 58.5 \mathrm{~Gy} ; \alpha / \beta=10$ ) was preferred to conventional treatment regimens. Nevertheless, 6- and 12 months local control rates 87.5 and $52.5 \%$ were achieved. Based on previous studies, no significant positive effect of tumor dose escalation over $\mathrm{BED}_{10} 60 \mathrm{~Gy}(\alpha / \beta=10)$ on overall survival in this highrisk patient subgroup exists [10].

Based on the analysis by Kaster et al., the relationship between BED and survival is moderately strong and demonstrated a moderate linear relationship

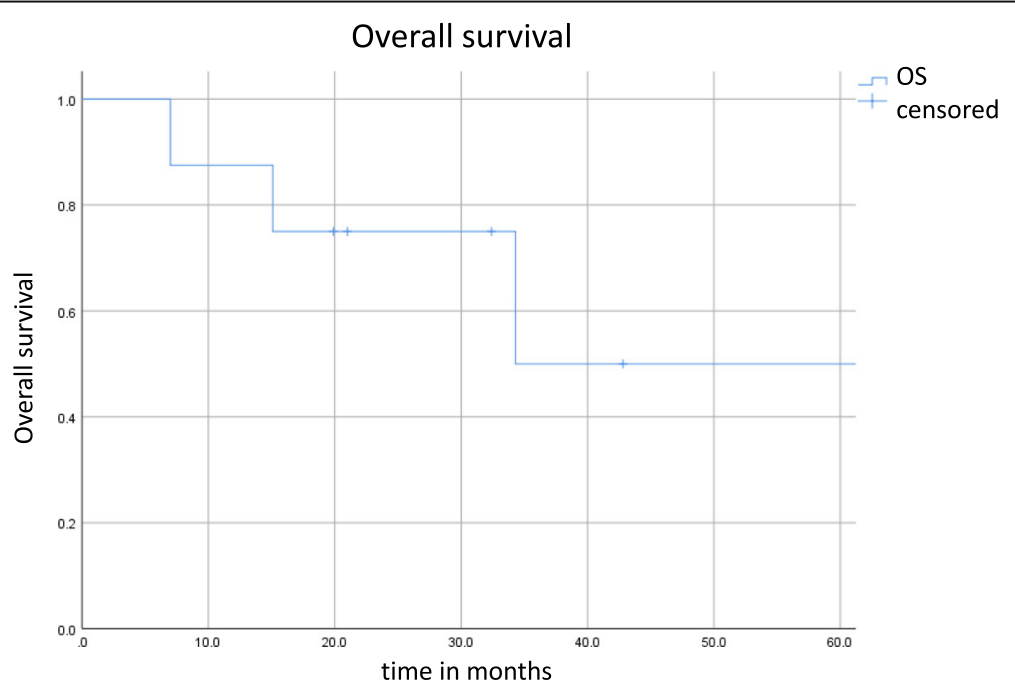

Fig. 3 Kaplan-Meier curve for overall survival. Tick marks indicate censoring 
between lesional BED and overall survival in the order of an absolute survival benefit up to a maximum $0.7 \%$ for every 1 Gy increase including moderate hypofractionation protocols.

The evaluation of PFT parameters did not demonstrate significant decline in VC, FEV1 nor DLCO-SB. These results are generally in accordance with previously reported on SABR for predominantly medically inoperable earlystage NSCLC [11, 12]. Stone et al. demonstrated although statistically significant, nearly all declines in PFTs as G1 on the RTOG scale and PFT declines to not be associated with inferior survival [11]. Stanic and colleagues observed that poor baseline PFT did not predict pulmonary toxicity nor decreased overall survival after SABR and concluded that poor baseline PFT alone should not be used to exclude patients with early stage lung cancer from treatment with SABR [12]. This formed the basis for our rationale in treating the patients in the current study. Poor initial PS and strongly diminished pulmonary function did not seem to predict excessive pulmonary toxicity nor inferior survival.

Certainly, confirmation of these results in a prospective setting enrolling a larger number of patients is absolutely imperative. As such, we initiated a single-centre study investigating this promising protocol in a previously neglected patient cohort.

Acknowledging the weaknesses of the current analysis, the small sample size cannot be overlooked as well as the inherent shortcomings of its retrospective nature. Nevertheless, to the best of our knowledge, this is the first analysis addressing feasibility of Hypo-IGRT in this high-risk patient cohort with poor performance status and diminished lung function. Indeed, some might question our rationale and might deem this protocol as highly risky, however our results could dispel such claims as no grade 3,4 and 5 toxicities were reported.

\section{Conclusion}

Hypo-IGRT can be considered for individual and closely monitored patients with locally advanced node-positive NSCLC with highly compromised pulmonary function. No severe pulmonary toxicity and significant decline of pulmonary function parameters was observed in our cohort. Currently, this protocol is being assessed in an ongoing single-centre prospective study.

\footnotetext{
Abbreviations

18F-FDG-PET/CT: Positron emission tomography with 2-deoxy-2-[fluorine-18] fluoro-d-glucose integrated with computed tomography; 4D-CT: Fourdimensional computed tomography; BED: Biologically effective dose; BSC: Best supportive care; COPD: Chronic obstructive pulmonary disease; CRT: Chemoradiotherapy; CT: Computed tomography; CTV: Clinical target volume; DLCO-SB: Single-breath diffusing capacity of the lung for CO; ECOG: Eastern Cooperative Oncology Group; FEV1: Forced expiratory volume in $1 \mathrm{~s}$; GTV: Gross tumour volume; Hypo-IGRT: Hypofractionated thoracic irradiation; IBM: International Business Machines Corporation;

ICRU: International Commission on Radiation Units \& Measurements;
}

ITV: Internal target volume; LA: locally advanced; MLD: Mean lung dose; MRI: Magnetic Resonance Imaging; NSCLC: Non-small cell lung cancer; OAR: Organs at risk; OS: Overall survival; PFS: Progression-free survival; PFT: Pulmonary function tests; PS: Performance score; PTV: Planning target volume; RTOG: Radiation Therapy Oncology Group; SABR: Stereotactic ablative radiotherapy; SPSS: Statistical package for the Social Sciences; TNM: Tumor-Node-Metastasis; V15: The volume of normal lung receiving 15 Gy; V20: The volume of normal lung receiving 20 Gy; VC: Vital Capacity; a/ $\beta$ : alpha/beta ratio

\section{Acknowledgements}

The piece has not been previously published and is not under consideration elsewhere. The persons listed as authors have given their approval for the submission.

\section{Authors' contributions}

CE and FM analysed and interpreted the data, performed the statistical analysis and wrote the manuscript. JT and OR helped with the statistical analysis and editing the manuscript. N-S S-H, LK, CW helped in drafting the manuscript. CB edited and critically revised the manuscript for valuable intellectual content. All authors read and gave their stamp of approval for the submission of the final version of the manuscript.

\section{Funding}

No funding was received.

\section{Availability of data and materials}

The datasets used and analysed during the current study are available from the corresponding author on reasonable request.

\section{Ethics approval and consent to participate}

All patients gave express written informed consent. This retrospective analysis is in compliance with the principles of the Declaration of Helsinki and its subsequent amendments. This work was approved by the Ethics Committee of the Ludwig Maximilian University of Munich.

\section{Consent for publication}

Not applicable.

\section{Competing interests}

The authors declare that they have no competing interests.

\section{Author details}

'Department of Radiation Oncology, University Hospital, LMU Munich, Marchioninistrasse 15, 81377 Munich, Germany. ${ }^{2}$ Comprehensive Pneumology Center Munich (CPC-M), Member of the German Center for Lung Research (DZL), Munich, Germany. ${ }^{3}$ German Cancer Consortium (DKTK), partner site Munich, Munich, Germany. ${ }^{4}$ Department of Pulmonology, Asklepios-Fachkliniken München-Gauting, Munich, Germany.

Received: 6 February 2019 Accepted: 22 May 2019

Published online: 04 September 2019

\section{References}

1. Antonia SJ, Villegas A, Daniel D, et al. Overall Survival with Durvalumab after Chemoradiotherapy in Stage III NSCLC. N Engl J Med. 2018;379(24):2342-50. https://doi.org/10.1056/NEJMoa1809697.

2. Curran WJ, Paulus R, Langer CJ, et al. Sequential vs Concurrent Chemoradiation for Stage III Non-Small Cell Lung Cancer: Randomized Phase III Trial RTOG 9410. JNCI J Natl Cancer Inst. 2011;103(19):1452-60. https://doi.org/10.1093/jnci/djr325.

3. Timmerman R, Paulus R, Galvin J, et al. Stereotactic Body Radiation Therapy for Inoperable Early Stage Lung Cancer. JAMA. 2010;303(11):1070. https:// doi.org/10.1001/jama.2010.261.

4. Senthi S, Lagerwaard FJ, Haasbeek CJ, Slotman BJ, Senan S. Patterns of disease recurrence after stereotactic ablative radiotherapy for early stage non-small-cell lung cancer: a retrospective analysis. Lancet Oncol. 2012;13(8): 802-9. https://doi.org/10.1016/S1470-2045(12)70242-5.

5. Amini A, Lin SH, Wei C, Allen P, Cox JD, Komaki R. Accelerated hypofractionated radiation therapy compared to conventionally fractionated 
radiation therapy for the treatment of inoperable non-small cell lung cancer. Radiat Oncol. 2012;7(1):33. https://doi.org/10.1186/1748-717X-7-33.

6. Agolli L, Valeriani M, Bracci S, et al. Hypofractionated Image-guided Radiation Therapy (3Gy/fraction) in Patients Affected by Inoperable Advanced-stage Non-small Cell Lung Cancer After Long-term Follow-up. Anticancer Res. 2015;35(10):5693-700 http://www.ncbi.nlm.nih.gov/ pubmed/26408745. Accessed 5 Jan 2019.

7. Westover KD, Loo BW, Gerber DE, et al. Precision hypofractionated radiation therapy in poor performing patients with non-small cell lung cancer: phase 1 dose escalation trial. Int J Radiat Oncol Biol Phys. 2015;93:72-81.

8. Swanick CW, Lin SH, Sutton J, et al. Use of simultaneous radiation boost achieves high control rates in patients with non-small-cell lung cancer who are not candidates for surgery or conventional chemoradiation. Clin Lung Cancer. 2015;16(2):156-63. https://doi.org/10.1016/j.cllc.2014.10.005.

9. Pollom EL, Qian Y, Durkee BY, et al. Hypofractionated Intensity-Modulated Radiotherapy for Patients With Non-Small-Cell Lung Cancer. Clin Lung Cancer. 2016;17(6):588-94. https://doi.org/10.1016/i.cllc.2016.05.024.

10. Nguyen LN, Komaki R, Allen P, Schea RA, Milas L. Effectiveness of accelerated radiotherapy for patients with inoperable non-small cell lung cancer (NSCLC) and borderline prognostic factors without distant metastasis: a retrospective review. Int J Radiat Oncol. 1999;44(5):1053-6. https://doi.org/10.1016/S0360-3016(99)00130-3.

11. Stone B, Mangona VS, Johnson MD, Ye H, Grills IS. Changes in Pulmonary Function Following Image-Guided Stereotactic Lung Radiotherapy. J Thorac Oncol. 2015;10(12):1762-9. https://doi.org/10.1097/JTO.0000000000000670.

12. Stanic S, Paulus R, Timmerman RD, et al. No Clinically Significant Changes in Pulmonary Function Following Stereotactic Body Radiation Therapy for Early- Stage Peripheral Non-Small Cell Lung Cancer: An Analysis of RTOG 0236. Int J Radiat Oncol. 2014;88(5):1092-9. https://doi.org/10.1016/j.jjrobp. 2013.12.050.

13. Manapov F, Roengvoraphoj O, Li M, Eze C. Moderate hypofractionated image-guided thoracic radiotherapy for locally advanced node-positive non-small cell lung cancer patients with very limited lung function: A case report. Radiat Oncol J. 2017;35(2). https://doi.org/10.3857/roj.2017.00129.

14. Kong F-M, Ten Haken RK, Schipper MJ, et al. High-dose radiation improved local tumor control and overall survival in patients with inoperable/ unresectable non-small-cell lung cancer: Long-term results of a radiation dose escalation study. Int J Radiat Oncol. 2005;63(2):324-33. https://doi.org/ 10.1016/j.jijobp.2005.02.010.

15. Kong F-M, Ten Haken RK, Schipper M, et al. Effect of Midtreatment PET/CTAdapted Radiation Therapy With Concurrent Chemotherapy in Patients With Locally Advanced Non-Small-Cell Lung Cancer. JAMA Oncol. 2017; 3(10):1358. https://doi.org/10.1001/jamaoncol.2017.0982.

16. Gore EM, Hu C, Sun AY, et al. Randomized Phase II Study Comparing Prophylactic Cranial Irradiation Alone to Prophylactic Cranial Irradiation and Consolidative Extracranial Irradiation for Extensive-Disease Small Cell Lung Cancer (ED SCLC): NRG Oncology RTOG 0937. J Thorac Oncol. 2017;12(10): 1561-70. https://doi.org/10.1016/j.jtho.2017.06.015.

17. Wood DE, Chair V, Aisner DL, et al. NCCN Guidelines Version 3.2019 NonSmall Cell. Lung Cancer. 2019; https://www.nccn.org/professionals/ physician_gls/pdf/nscl.pdf. Accessed 31 Mar 2019.

18. Kaster TS, Yaremko B, Palma DA, Rodrigues GB. Radical-Intent Hypofractionated Radiotherapy for Locally Advanced Non-Small-Cell Lung Cancer: A Systematic Review of the Literature. Clin Lung Cancer. 2015;16(2): 71-9. https://doi.org/10.1016/J.CLLC.2014.08.002.

19. Werner-Wasik M, Scott C, Cox JD, et al. Recursive partitioning analysis of 1999 radiation therapy oncology group (RTOG) patients with locallyadvanced non-small-cell lung cancer (LA-NSCLC): Identification of five groups with different survival. Int J Radiat Oncol. 2000;48(5):1475-82. https://doi.org/10.1016/S0360-3016(00)00801-4

\section{Publisher's Note}

Springer Nature remains neutral with regard to jurisdictional claims in published maps and institutional affiliations.

Ready to submit your research? Choose BMC and benefit from:

- fast, convenient online submission

- thorough peer review by experienced researchers in your field

- rapid publication on acceptance

- support for research data, including large and complex data types

- gold Open Access which fosters wider collaboration and increased citations

- maximum visibility for your research: over $100 \mathrm{M}$ website views per year

At BMC, research is always in progress.

Learn more biomedcentral.com/submissions 